CUPAUAM. 16-1989, 211-231

\title{
EL YACIMIENTO DE LA CAPELLANA (PINTO, MADRID) NUEVOS DATOS SOBRE LAS RELACIONES ENTRE LAS COSTAS MERIDIONALES Y LA SUBMESETA SUR DURANTE LA PRIMERA EDAD DEL HIERRO
}

\author{
Ma CONCEPCION BlasCo BOSQUED \\ FCo. JaVier Baena PREYSLER \\ UNIVERSIDAD AUTONOMA DE MADRID
}

\section{Resumen}

En este trabajo se da a conocer un nuevo yacimiento de la Primera Edad del Hierro situado en el término de Pinto (Madrid). Los materiales recuperados en este hábitat son un claro reflejo de las relaciones que esta zona mantiene con las regiones peninsulares meridionales y, más concretamente, con las primeras colonias fenicias establecidas en nuestras costas.

\section{Summary}

This work presents a new first Iron Age site found near the village of Pinto (Madrid). The findings in this settlement are a clear example of the relationships between the Meseta and meridional areas, and particulary with the first Phoenician coastal colonies established in Southern Spain

Desde hace sólo unos años comienza a definirse en la región de Madrid un horizonte cultural situado entre el Bronce Final de la zona, representado por Cogotas I, y la segunda Edad del Hierro, caracterizada por la llegada de elementos ibéricos que se aculturan con las tradiciones locales. Dicho horizonte puede situarse cronológicamente entre mediados del siglo VIII y comienzos del V antes de Cristo, cubriendo así un importante vacío que se había intentado rellenar con una excesiva dilatación del Horizonte Cogotas I que se le hacía conectar con los prolegómenos de la iberización. A pesar de este avance son todavía pocos los yacimientos de este horizonte que han sido excavados y por tanto no contamos con datos suficientes para conocer el desarrollo y periodización de esta etapa de algo más de dos siglos de duración.

Como ya hemos apuntado en otro trabajo (Blasco, Calle y Sanchez Capilla, 1990), el horizonte que nos ocupa se caracteriza por la desaparición, casi repentina, de los más característicos fósiles directores cerámicos del Horizonte Cogotas I, que son sustituídos por nuevos conjuntos 
vasculares que, aunque evidencian una clara raigambre local, presentan también una importante renovación de indudable inspiración meridional. Precisamente el yacimiento que estudiamos en este trabajo manifiesta, de forma bastante clara, cuáles son los impusos que propician o, al menos, aceleran el proceso de cambio entre el Bronce Final y la Primera Edad del Hierro en esta región, a pesar de que el estado de deterioro en que se encontraba en el momento de su excavación no haya permitido aprovechar toda la documentación que hubiera ofrecido de encontrarse en un mejor estado de conservación.

Por otra parte, las características de las cerámicas obtenidas en La Capellana nos permiten suponer la existencia de algunas diferencias temporales entre los yacimientos de este horizonte cultural al detectarse una evolución favorecida por la intensificación de las relaciones con las regiones más meridionales hasta desembocar, casi sin solución de continuidad, en la iberización.

El sitio de La Capellana se encuentra ubicado en el término municipal de Pinto, a la altura del km. 20 izquierda de la Carretera nacional VI, Madrid-Andalucía. Se asienta en terrenos neógenos, a poco más de dos kilómetros, al sur del arroyo Culebro en un lugar abierto de amplia visibilidad. En la actualidad la zona se dedica a tierras de labor de agricultura de secano, que alterna con algunas manchas de olivos.

La identificación del yacimiento se produjo en el curso de la realización de la Carta arqueológica de Pinto llevada a cabo por los licenciados Juan Ayllon y Virginia Recuero quienes recogieron en un terreno en barbecho abundante material cerámico asociado a una extensa mancha oscura de tierras muy sueltas. La abundancia de material mueble en superficie era un síntoma evidente del importante grado de deterioro del yacimiento. Este hecho, unido a la reclasificación de los terrenos como urbanizables, nos impulsó a solicitar de la Comunidad de Madrid el correspondiente permiso para realizar una excavación de urgencia que nos permitiera evaluar el interés del yacimiento, su extensión y el grado de conservación en que se encontraba.

Los trabajos se llevaron a cabo en los meses de enero-febrero de 1990, planteándose la ejecución de una serie de sondeos en diversos puntos seleccionados del yacimiento, con el fin de comprobar la existencia de posibles variaciones internas y facilitar la realización de una planimetría parcial.

En superficie, además de los restos muebles, destacaba la existencia de una extensa mancha oscura de tierra muy suelta que presentaba planta irregular aunque de tendencia oval, con unos ejes de 52 por 30 metros. Hacia el sureste el perfil era sensiblemente más sinuoso que en el resto del perímetro, posiblemente producto de la remoción realizada por las máquinas empleadas en las labores agrícolas (Fig. 1). Por otra parte, en la zona suroeste de la parcela, fuera de la mancha oscura y en un corte natural del terreno producido por una pequeña vaguada que lo limita, eran visisbles una serie de piedras de gran tamaño.

Teniendo en cuenta estas evidencias y los puntos de mayor intensidad de la mancha, se realizaron cinco cuadrículas de dos por dos metros; una de ellas se trazó en un punto de la periferia de la mancha, por su lado norte y las otras cuatro en el interior de la misma, dentro de la zona donde alcanzaba mayor intensidad. Además, se abrió una amplia cata de cinco por cinco metros, en el corte del terreno donde eran visibles las piedras, con el fin de comprobar si su disposición era intencionada y si se podía confirmar la coetaneidad de este aparente murete con los hallazgos dispersos en la amplia mancha.

Todas las cuadrículas, a excepción de la cata suroeste, aportaron una estratigrafía muy similar, con cuatro niveles, relativamente diferenciados (Fig. 2):

I.-Tierra vegetal de color muy oscuro y muy suelta que proporcionó el mayor volumen de 


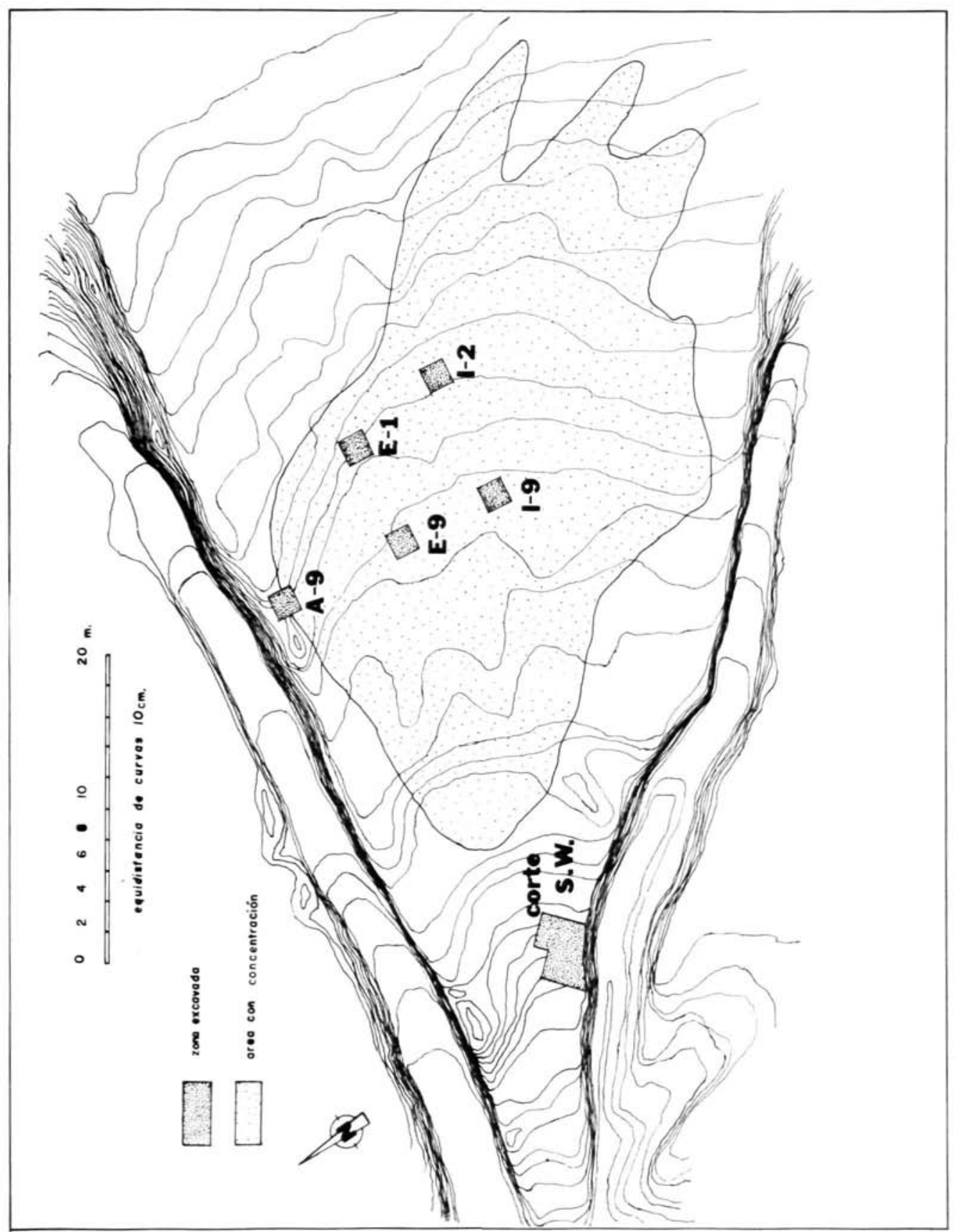

Figura 1. Plano general del yacimiento con la planta de la gran mancha oscura y la situación de las cuadrículas. 


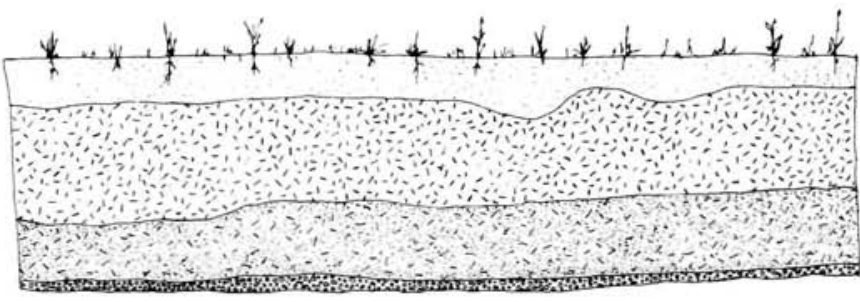

corte at

Dertil 5

rodos a eneda

E $1 / 10$

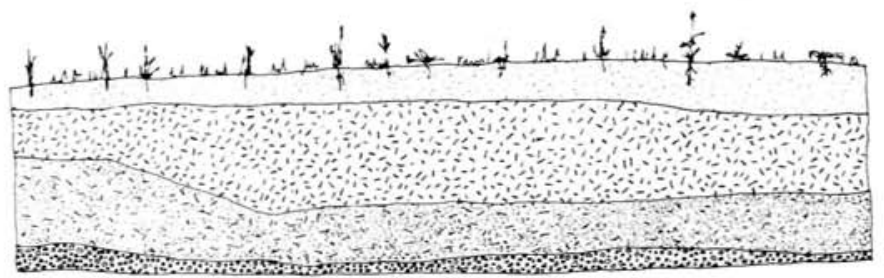

corts 12

Dertil 0
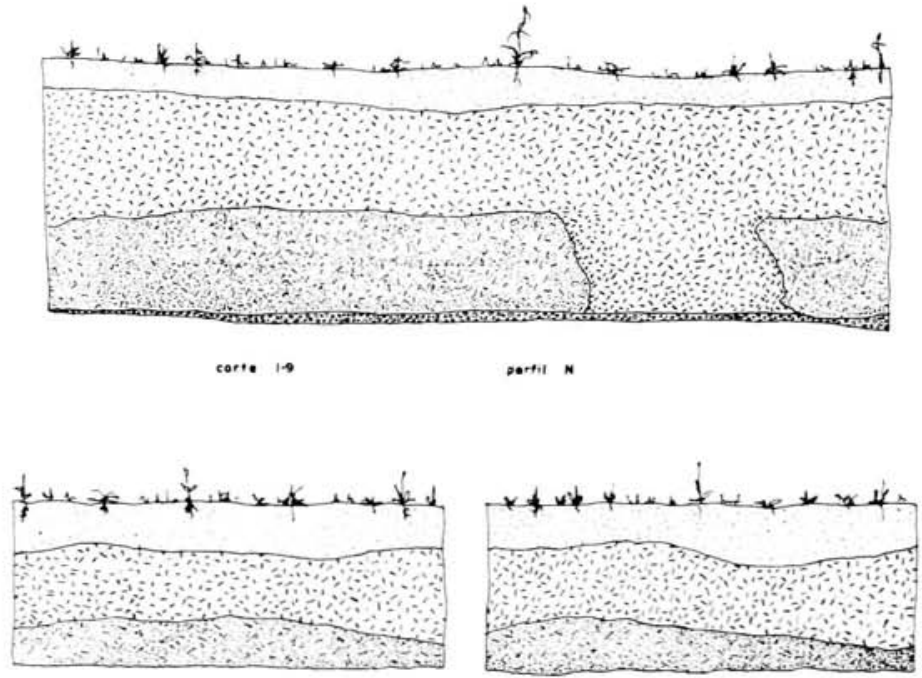

Derfil $\mathrm{N}$

corte E-1

norfil E
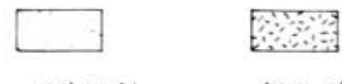

rixis

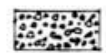

nivel vesetel

nerra give

nerre marron

perre anerille

Figura 2. Cortes estratigráficos de los niveles observados de las diferentes cuadrículas. 


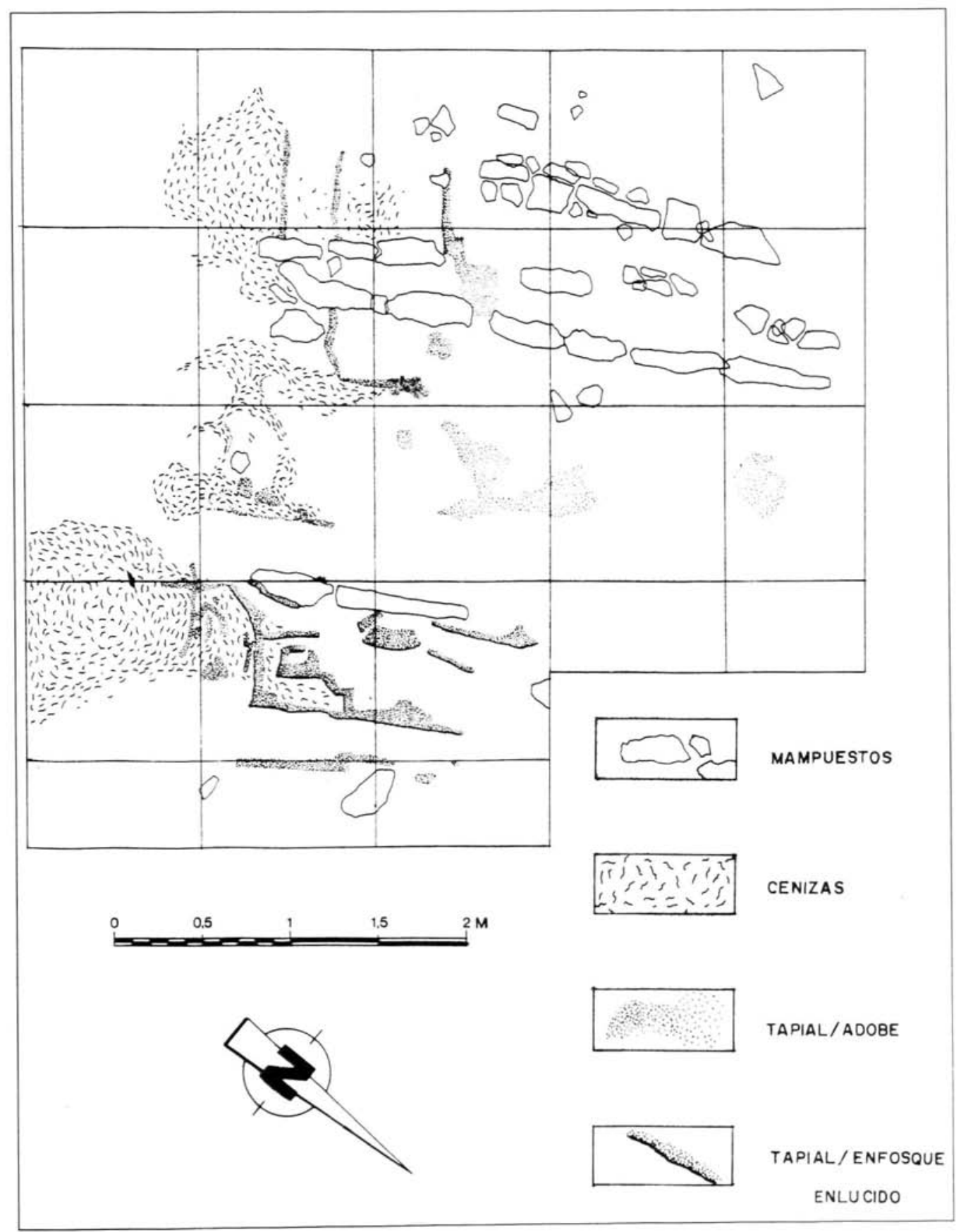

Figura 3. Planta de la cata suroeste con la situación de los bloques de sílex alineados. 
material, el cual aparecía muy rodado. El intenso color negro detectaba la existencia de abundante material orgánico, posiblemente procedente del suelo de ocupación y de los propios materiales de construcción de las unidades domésticas.

II.-Nivel de tierra muy suelta de color gris cenizoso, con un volumen importante de restos arqueológicos bastante fragmentados. En él se detectaban manchas más oscuras, al parecer, procedentes de materiales orgáanicos presentes en las posibles estructuras inmuebles, los cuales se encontraban en posición secundaria y muy fragmentados por lo que no ofrecieron ningún dato relacionable con las plantas o tamaños de las estructuras.

III.-Nivel de tierra marronacea bastante más compacto que los dos más superficiales. El material arqueológico se encontraba concentrado en determinadas bolsadas, siendo muy escaso en el resto del estrato.

IV.-Nivel de base, compacto y de color amarillento, totalmente estéril desde el punto de vista arqueológico.

En la cuadrícula, abierta en la zona suroeste del yacimiento, bajo el nivel de tierra vegetal (I), se encontraba el estrato de tierra marronacea (III), en el cual aparecían hincados una serie de bloques líticos alineados, así como restos de posibles manteados y tapial, además de manchas cenizosas. Todo ello descansaba sobre el nivel de base de color amarillento.

Desgraciadamente, en el momento de la excavación. el yacimiento se encontraba arrasado por la acción de las máquinas agrarias ya que el suelo de ocupación estaba situado a muy pocos centímetros de la superficie actual. A ello hay que añadir que las posibles estructuras arquitectónicas debieron de estar realizadas, en su mayoría, en materiales perecederos o con barro simplemente seco al sol, lo que ha facilitado su destrucción y la total disgregación de los materiales constructivos, impidiendo una aproximación a su conocimiento. Excepcionalmente en la cata suroeste se localizaron una serie de bloque líticos, concretamente de silex, hincados y alineados en dirección norte-sur que podrían ser los restos, muy perdidos, de alguna estructura cuyas dimensiones y características son difíciles de conocer por el escaso tramo que se conserva y la ausencia de esquinas, vanos e incluso de posibles revestimientos .

Estos bloques crean tres muretes paralelos separados entre sí metro y medio y 40 centímetros respectivamente. Mientras que los dos exteriores están creados por una única hilada, el central presenta doble paramento que deja en su interior unos 20 centímetros rellenos con tierra y pequeñas piedras (Fig. 3 ). La diferente técnica constructiva podría indicar distintos momentos de ejecución correspondientes a remodelaciones de espacios o a la erección de estructuras diferentes que no parecen haber estado superpuestas. La mayor originalidad de estos restos es su elaboración con bloques de sílex, una piedra poco apta para trabajos de cantería por su gran dureza y dificultad de talla, sin embargo es la única piedra disponible en la zona, lo que obligó a utilizarla, incluso para aspectos poco apropiados, como es la actividad constructiva.

Posiblemente estos bloques se emplearon exclusivamente para los zócalos, ya que no existen otras piedras en la zona inmediata al yacimiento, por el contrario, el alzado se debió de realizar a base de adobes o tapial, revestidos con manteado de barro para disimular la tosquedad de su trabajo, ello explica la existencia, en las proximidades de los bloques de piedra alineados, tanto de restos de enlucidos o manteado como de adobes o tapial. Un aspecto que interesa destacar es el trazado rectilíneo de estos muretes ya que, hasta el momento, todas las estructuras conocidas en yacimientos de este mismo horizonte, en ambas mesetas, presentan cerramientos curvilíneos, de tendencia circular u oval. No obstante, si tenemos en cuenta los datos proporcionados por yacimientos de otras áreas, como es el sudeste peninsular, no debe extrañarnos esta circunstancia ya 
que en esa región más meridional, durante esta etapa, las estructuras rectilíneas son más frecuentes que las curvilíneas, siendo especialmente notable el caso de Peña Negra de Crevillente donde ambos tipos de estructuras aparencen indistintamente sin un significado cronológico (González Prats, A.: 1985, pp. 153-158).

La conservación de estructuras en este punto del yacimiento se explicaría, tanto por la naturaleza lítica del material empleado para la ejecución de los zócalos, como por su situación, junto al escarpe natural, en una zona donde la superficie se estrecha bastante y, por tanto, no se cultiva desde la introducción de las máquinas por la dificultad que entraña maniobrar con grandes equipos, de manera que en este punto concreto no ha habido una remoción importante del terreno, a diferencia de lo que ocurre en el resto de la parcela, donde se ha producido una intensa alteración como consecuencia de la acción de las máquinas, hasta una profundidad superior a los 50 centimetros.

A pesar de la total desaparición del suelo de ocupación y, en consecuencia, la pérdida de la posición originaria del material mueble, así como la destrucción de todos los restos inmuebles, a excepción de los zócalos antes descritos, el yacimiento de La Capellana resulta de enorme interés por las características de sus cerámicas, el único conjunto de elementos muebles suficientemente importante por su volumen y por su significado al ofrecer una relevante información para el conocimiento de las relaciones entre los grupos peninsulares establecidos en las regiones costeras meridionales y las gentes del interior.

Por el acabado y grosor de las pastas se distinguen dos grandes grupos vasculares: la cerámica común que alcanza, aproximadamente, el $83 \%$ del conjunto y la cerámica fina que supone en torno al $17 \%$, una proporción bastante similar a la que encontramos en la mayoría de los conjuntos domésticos de la Prehistoria reciente.

Entre los fragmentos que hemos incluído en el primero de estos grupos, sólo el $10 \%$ fueron realizados con fuego oxidante y el resto fueron cocidos en hornos reductores. Como suele ocurrir entre las cerámicas comunes, los ejemplares decorados son excepcionales ya que sólo suponen un 0 '3 \% de los fragmentos de este grupo y cuando presentan ornamentación ésta se reduce, generalmente, a incisiones o impresiones de dedos y/o uñas sobre los labios o sobre el hombro del recipiente, creando sencillos frisos constituídos por una hilada incisiones o impresiones (Fig. 4). También podemos considerar como elemento decorativo el tratamiento de cepillado que encontramos en casi el 3\% de las piezas de este apartado de cerámicas comunes, la función ornamental de este acabado reside en que normalmente se aplica a una parte de la superficie externa para contrastar con el resto de esa superficie externa que suele estar simplemente alisada. Tanto las impresiones e incisiones como el cepillado y, sobre todo, la combinación de ambos tratamientos ornamentales son propios de la mayoría de los conjuntos de cerámica común del Hierro antiguo peninsular, pero los encontramos con especial frecuencia en los niveles del Bronce Final orientalizante de yacimientos encuadrados en el área del suroeste peninsular (Almagro, M. 1977, pp. 134-136).

Un apartado distinto lo constituye un pequeño lote de fragmentos, pertenecientes a recipientes de paredes relativamente gruesas y tamaño medio o grande que se decoran con fuertes incisiones creando entramados reticulados (Fig. 5, $\mathrm{n}^{\circ} \mathrm{6}$ a 8) desarrollados en la cara interna, o que ornamentan su cara externa con incisiones que describen ángulos u otros diseños geométricos (Fig. $5 n^{\circ} 3$ a 5 y fig 6, n० 10). Los entramados incisos desarrollados en la cara interna son bastante raros y tienen cierta similitud con la decoración que presentan los fragmentos de morillos recuperados en este mismo yacimiento o en el poblado de Alhonoz (López Palomo, L. A. 1981, 


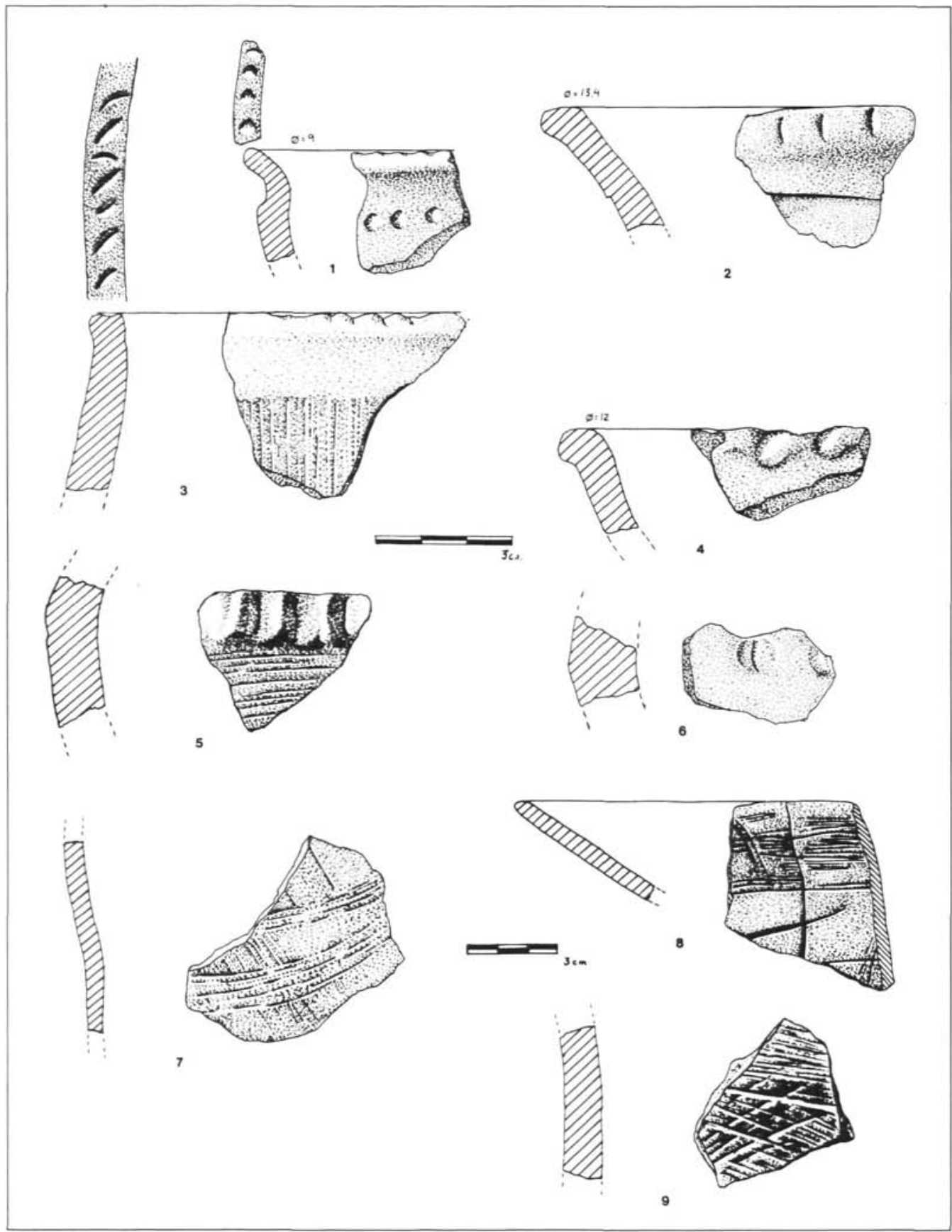

Figura 4. Decoración de recipientes comunes. 


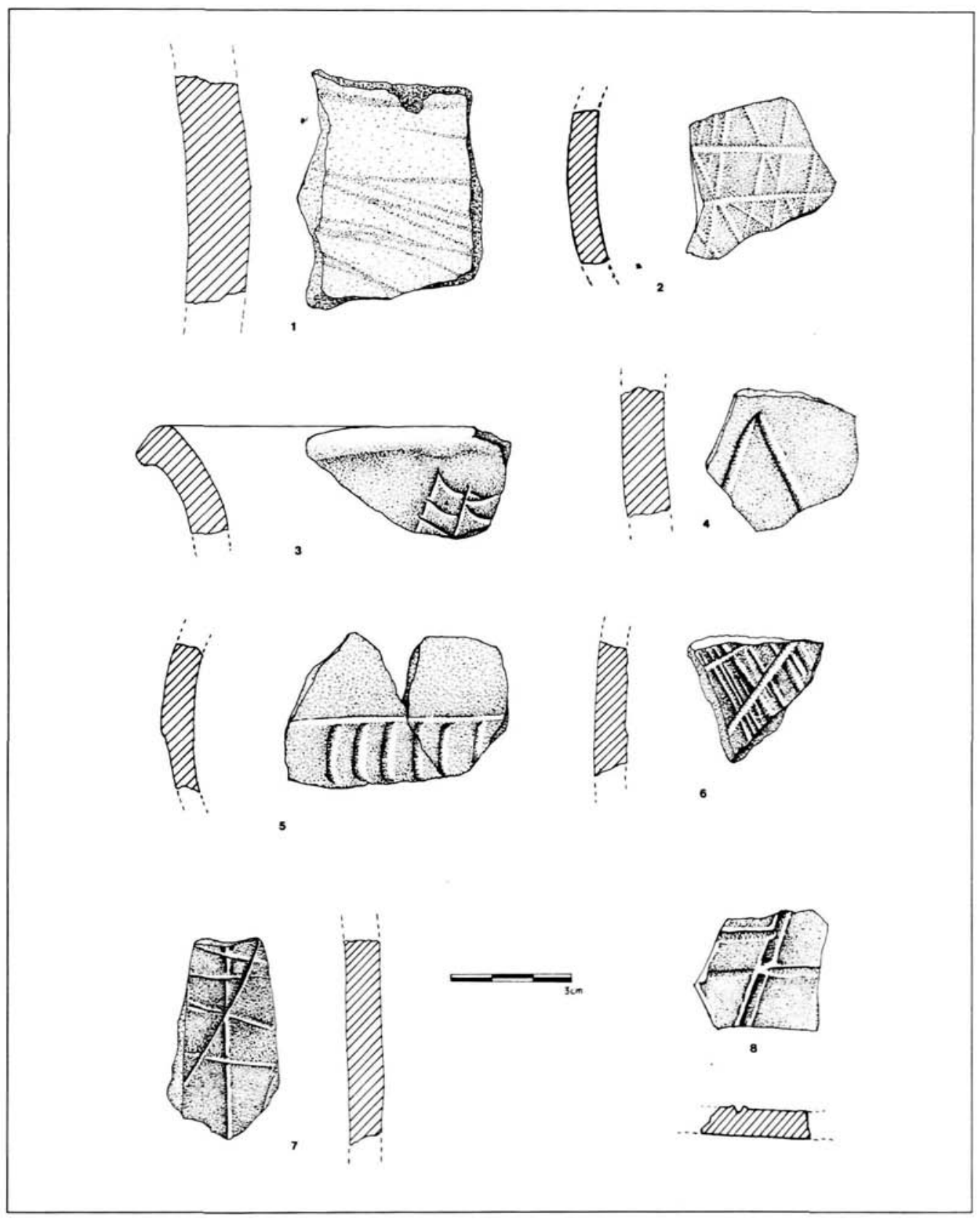

Figura 5. No 1 decoración bruñida; n 2, decoración bruñida e incisa; no 3 a 8 diversos tipos de decoración incisa sobre cerámicas comunes. 
p. 159, fig 57 ) de donde también procede un plato ibérico con una retícula de profundas incisiones incisas realizadas sobre la cara interna (López Palomo, L.A..,1981, p. 143, Fig. 47), aunque esta pieza parece de cronología más avanzada que los materiales que ahora estudiamos. No descartamos que estos entramados incisos puedan ser una burda imitación de las retículas bruñidas, $\tan$ frecuentes en el bronce final del suroeste.

Poco podemos decir del aspecto formal de este conjunto pues no se conserva ningún recipiente completo, únicamente apuntar que todas las bases son planas (Fig. $6, n^{\circ} 8$ a 11 ), generalmente con talón. Así mismo, se puede deducir que existen tanto ollas con cuello que diferencia la boca del galbo, como recipientes simples de perfil troncocónico o de tendencia esférica (Fig. 6 $\mathrm{n}^{\circ} 1$ a 6). Desconocemos los elementos de suspensión de este lote vascular, aunque es probable que no tuvieran o que sirvieran como tales algunos mamelones plásticos que suelen ser relativamente frecuentes (Fig. 7, $\mathrm{n}^{\circ} 6$ a 10 ).

Aunque menos abundante, mucho más variada y significativa es la cerámica fina que presenta dos tipos de superficies claramente diferencias: negras o grises, bruñidas o espatuladas y con engobe o barniz rojo de excelente calidad que reproduce con total fidelidad las producciones fenicias del momento, aunque sobre prototipos realizados a mano, estas últimas suponen alrededor del $16 \%$ del total de los ejemplares finos y sus formas son similares a las producciones de superficias reductoras.

Se trata de un acabado que, desde hace ya tiempo, viene reconociéndose en yacimientos del Hierro antiguo del área meridional, como Cástulo, Galera, Peña Negra, etc. y que se han denominado "almagras"; desde hace poco tiempo, hemos comenzado a identificar también este engobe en diversos yacimientos madrileños de la Primera Edad del Hierro: Cerro de San Antonio, Sector III de Getafe, etc., y habíamos justificado su presencia como consecuencia de las relaciones existentes, en este momento, entre grupos indígenas de ambas áreas culturales, sin embargo, como veremos más adelante, pensamos que debe de reconsiderarse esta tesis y buscar su origen en las primeras producciones fenicias peninsulares.

Además, se han recogido algunos fragmentos negros con un acabado bruñido muy intenso que cubre totalmente la superficie de ambas caras, reproduciendo un aspecto casi vidriado, de extraordinario efectismo, calidad que, al igual que los engobes rojos, parece obtenerse también por la aplicación de óxidos férricos a los que la cocción reductora les proporciona ese color negro.

Entre las técnicas decorativas aplicadas a estos ejemplares finos, dominan las incisiones realizadas con punzones de distintas características (Fig. 8), entre ellas son dignos de mención las soleras con decoración o contramarcas incisas por su similitud con algunas bases procedentes de yacimientos de "época tartésica" del suroeste peninsular (Ruiz Mata, D. y Fernandez Jurado, J. 1986, láms.LXII y CV). Pero no faltan tampoco la pintura postcocción roja o bícroma (amarilla y roja) o las aplicaciones plásticas aunque, sin duda, la técnica más llamativa es el bruñido (Fig. 5,1 y 2) que en un par de ocasiones se aplica creando retículas que presentan una importante similiud con las que encontramos en producciones del Bronce final del suroeste, incluso por su aplicación en la cara interna del recipiente, si bien el bruñido se destaca con un somero acanalado ( Fig. 5, 2). El total de fragmentos finos decorados supone en torno al $1 \%$.

Con respecto a las formas conviene señalar la existencia de cuencos simples, hemiesféricos o troncocónicos, similares a algunos de los recipientes comunes, y de cazuelas carenadas o galbosas (Fig. 9), entre unos y otras dominan los recipientes de pequeñas dimensiones con base umbilicada y asas en forma de pequeños pezones de perforación vertical u horizontal. Otras veces, la sus- 


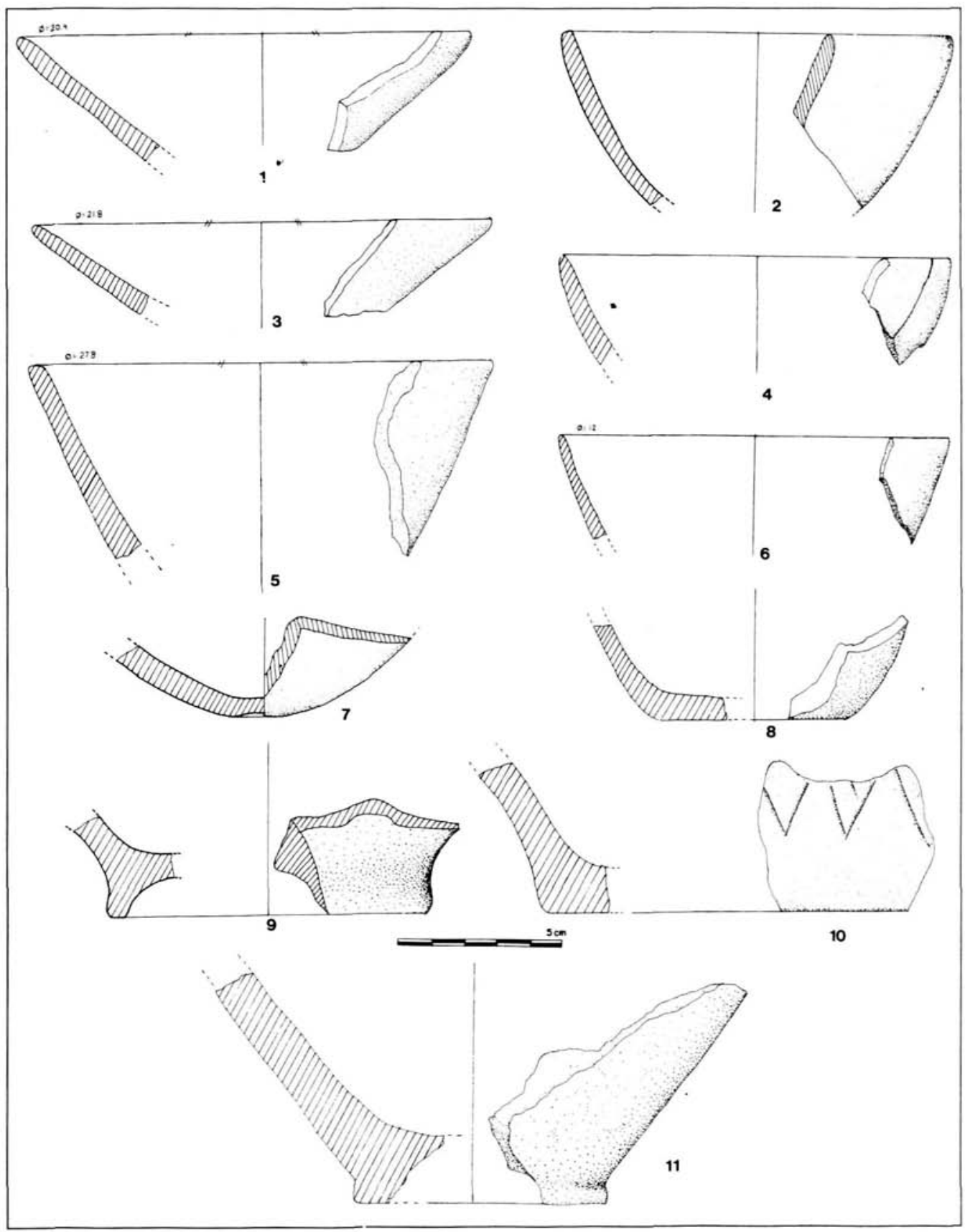

Figura 6. Diversos tipos de cuencos de cerámica fina y común y algunos ejemplos de bases, las de talón corresponden a ejemplares comunes. 


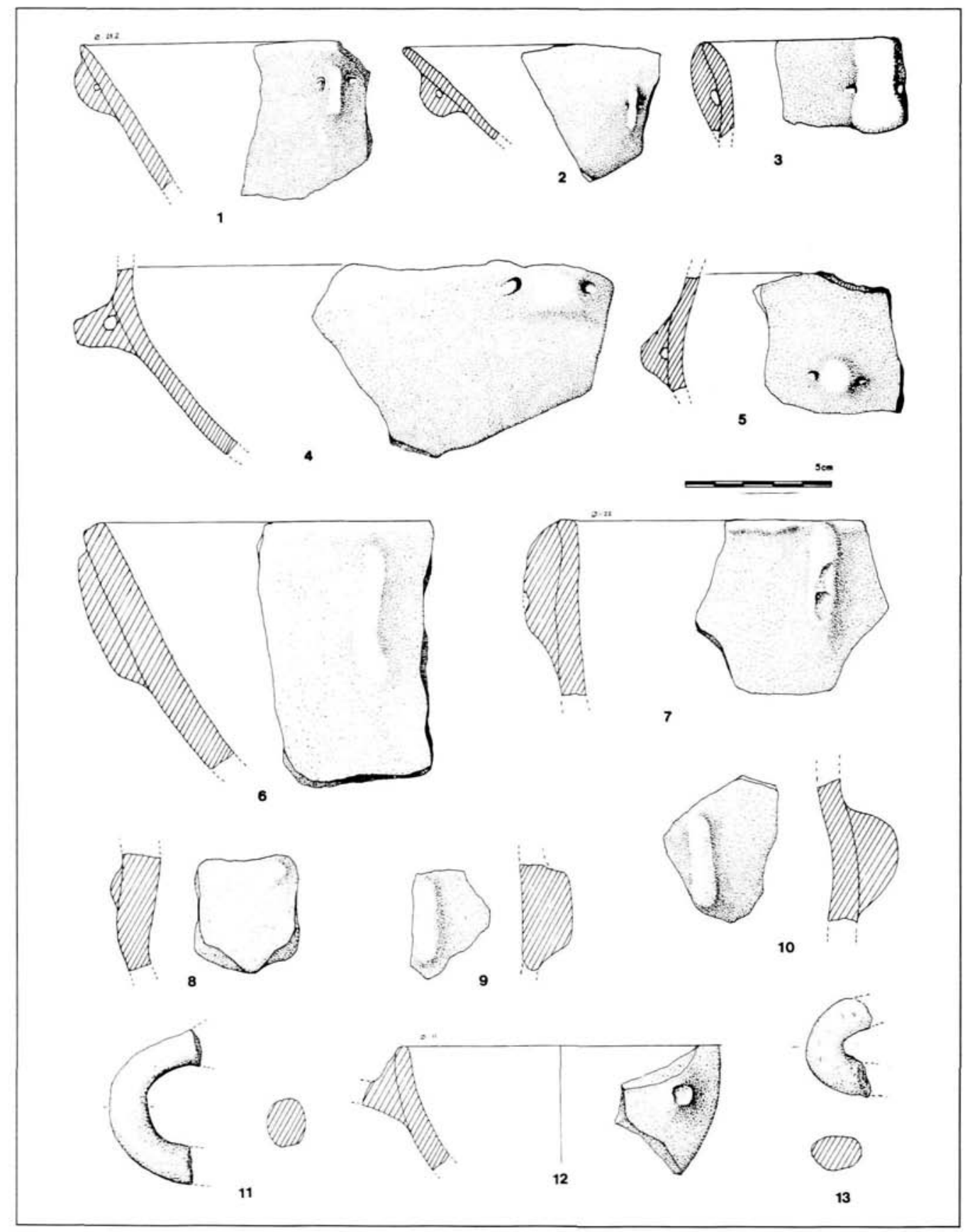

Figura 7. Elementos de suspensión. Los mamelones perforados son propios de las cerámicas finas, mientras que en los ejemplares comunes dominan los mamelones ciegos. 


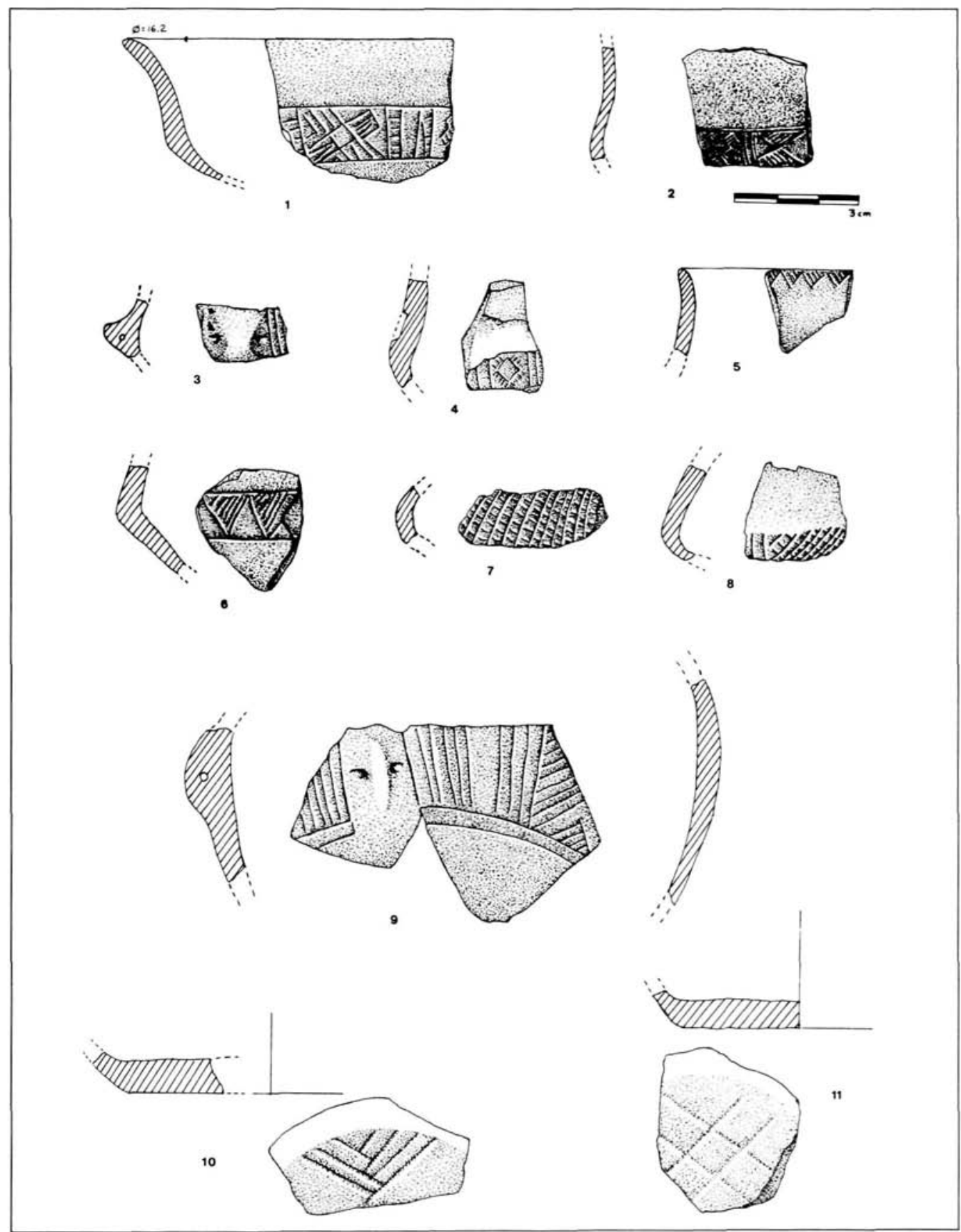

Figura 8. Fragmentos de ejemplares finos con decoración incisa. El no 1 tiene acabado de engobe rojo, mientras que el resto presenta superficies negras o grises. 

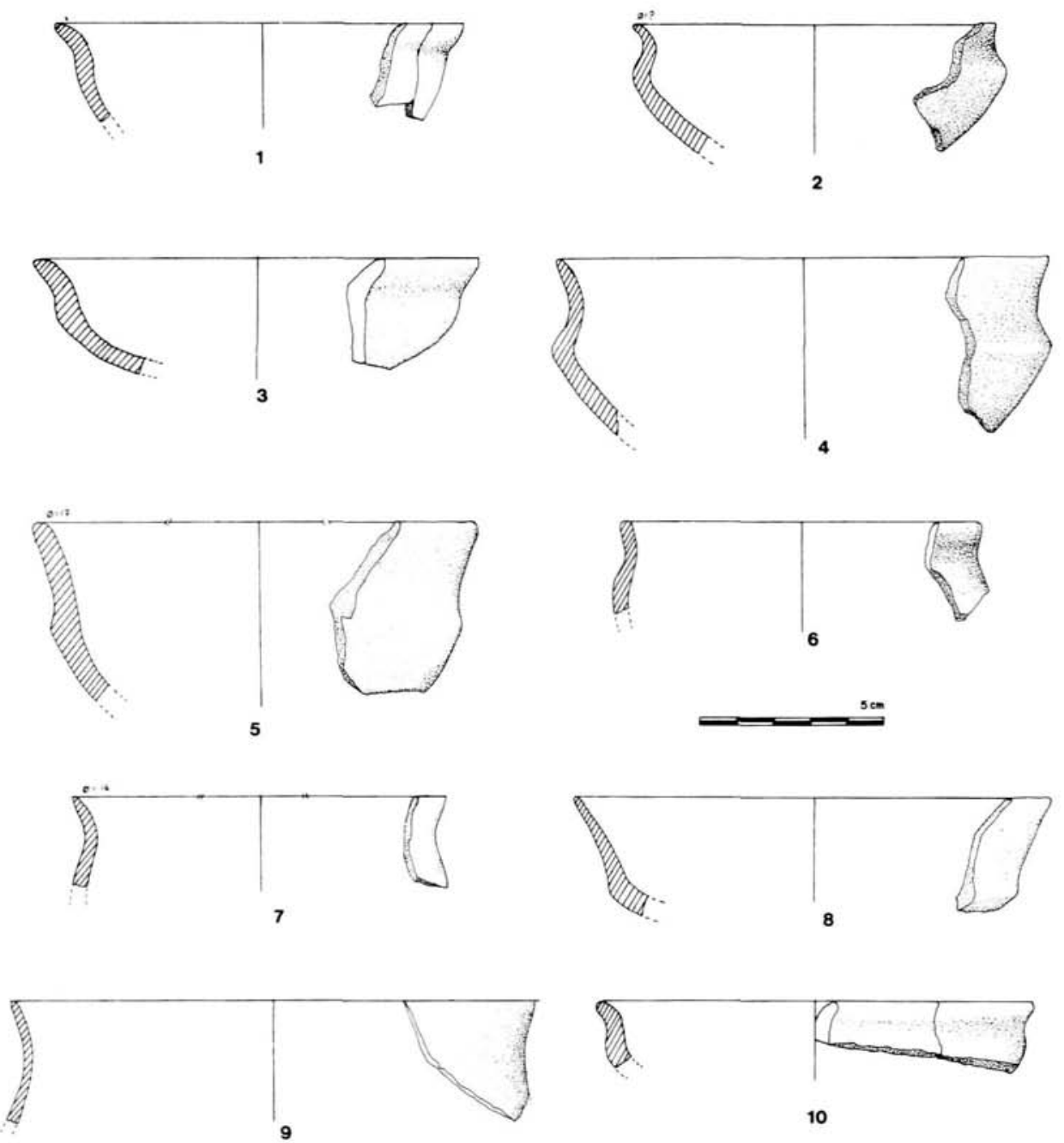

10
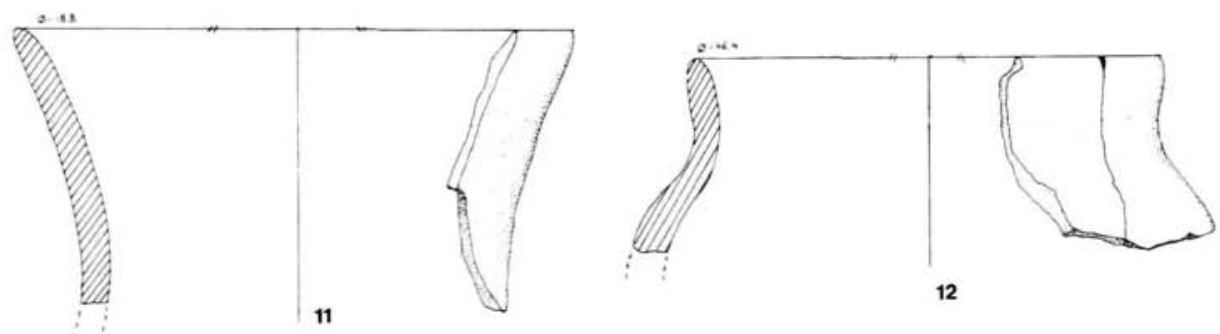

Figura 9. Variantes de cazuelas carenadas o globulares . 
pensión del recipiente se consigue mediante un par de perforaciones practicadas en las proximidades de la boca o, más excepcionalmente, con asas de sección circular (Fig. 7).

A pesar de estar realizados a mano, la mayoría de estos recipientes son de paredes muy finas, llegando a darse casos de suma delgadez que pueden incluirse dentro de los denominados de "cáscara de huevo" (Arteaga, O. y Serna, R., 1975) que encontramos en yacimientos del sureste, de cronología similar y cuyo coste de ejecución debía de ser altísimo, aunque su perfección les permitía competir con las producciones de torno que comenzaban a fabricarse en algunos alfares radicados dentro del ámbito de las colonias.

Mención aparte merecen los fragmentos de morillos (Fig. 10) ya que son piezas cuya presencia se detecta en la Península a partir del Bronce Final, siendo relativamente frecuentes en el área del alto Tajo (Blasco, Calle y Sanchez Capilla, 1990, p. 169 ). Sólo se han recuperado algunas partes inferiores de ejemplares de sección trapezoidal, a las que les falta el remate, aunque por su fragmentación desconocemos su aspecto final, en lo que se conservan, presentan las características propias de los ejemplares de este momento, más sencillos que los pertenecientes a época ibérica.

También conviene destacar la existencia de alguna lasca de sílex retocada, de varios huesos pulidos y recortados en forma de media arandela y, sobre todo, de un pequeño punzón de bronce con cabeza indicada y sección cuadrangular (Fig. 11), de sólo 34 milímetros de longitud por lo que, forzosamente, se usó enmangado, cicunstancia que se confirma por la pátina que se aprecia en la zona de la cabeza, la cual es producto del roce con un material poroso procedente del enmangue. Este tipo de punzón es similar, aunque de menor tamaño, a otro recuperado en el yacimiento madrileño del sector III de Getafe perteneciente al mismo horizonte cultural; su morfología contrasta con la de los biapuntados que aparecen en los conjuntos Cogotas I del Bronce Final de la zona (Martínez Navarrete y Mendez, 1983. p. 230, fig. 17)

El yacimiento responde a las características propias de los asentamientos de la I Edad del Hierro del Alto Tajo, aunque no se ubica en un lugar prominente, o en la terraza de un gran río, como suele ser habitual, sino en un paraje abierto y lejos de un cauce fluvial importante, en un punto de fácil comunicación, en la misma carretera nacional $\mathrm{V}$, en la zona intefluvial entre el Jarama y el Guadarrama, dentro del término municipal de Pinto, considerado el punto geográgico central de España. Su situación pudo haber facilitado las relaciones entre otras áreas, aunque la escasa potencia del yacimiento no permite pensar que nos encontremos ante un lugar de relaciones fijas y permanentes, sino más bien ante un punto cuya fácil accesibilidad, determinó el asentamiento de un grupo, cuya permanencia, aunque resulta difícil de precisar, no parece que fuera demasiado prolongada.

Lo cierto es que las gentes aquí asentadas mantenían o habían mantenido relaciones con algún enclave fenicio o su área de influencia de donde habrían aprendido la técnica del engobe o barniz rojo, del que llegaron a conseguir una extraordinaria calidad. Este acabado, sin embargo, no se asocia al torno del alfarero, como ocurre en el ámbito de las colonias, posiblemente porque el dominio de la rueda para la alfarería debía de requerir una cierta experimentación al ser una técnica lo suficientemente compleja como para no dominarla tras contactos, quizás demasiado fugaces, sin embargo, la excelente calidad del barniz permite suponer que los alfareros que la aplicaron debieron de haber visto su proceso de elaboración en factorías costeras, ya que resulta bastante extraño que se puedan conseguir esos resultados por la simple observación de productos acabados.

Como ya se ha apuntado, el acabado de barniz rojo lo encontramos prácticamente en todos los yacimientos de este horizonte de la región de Madrid, aunque, en los excavados hasta ahora 


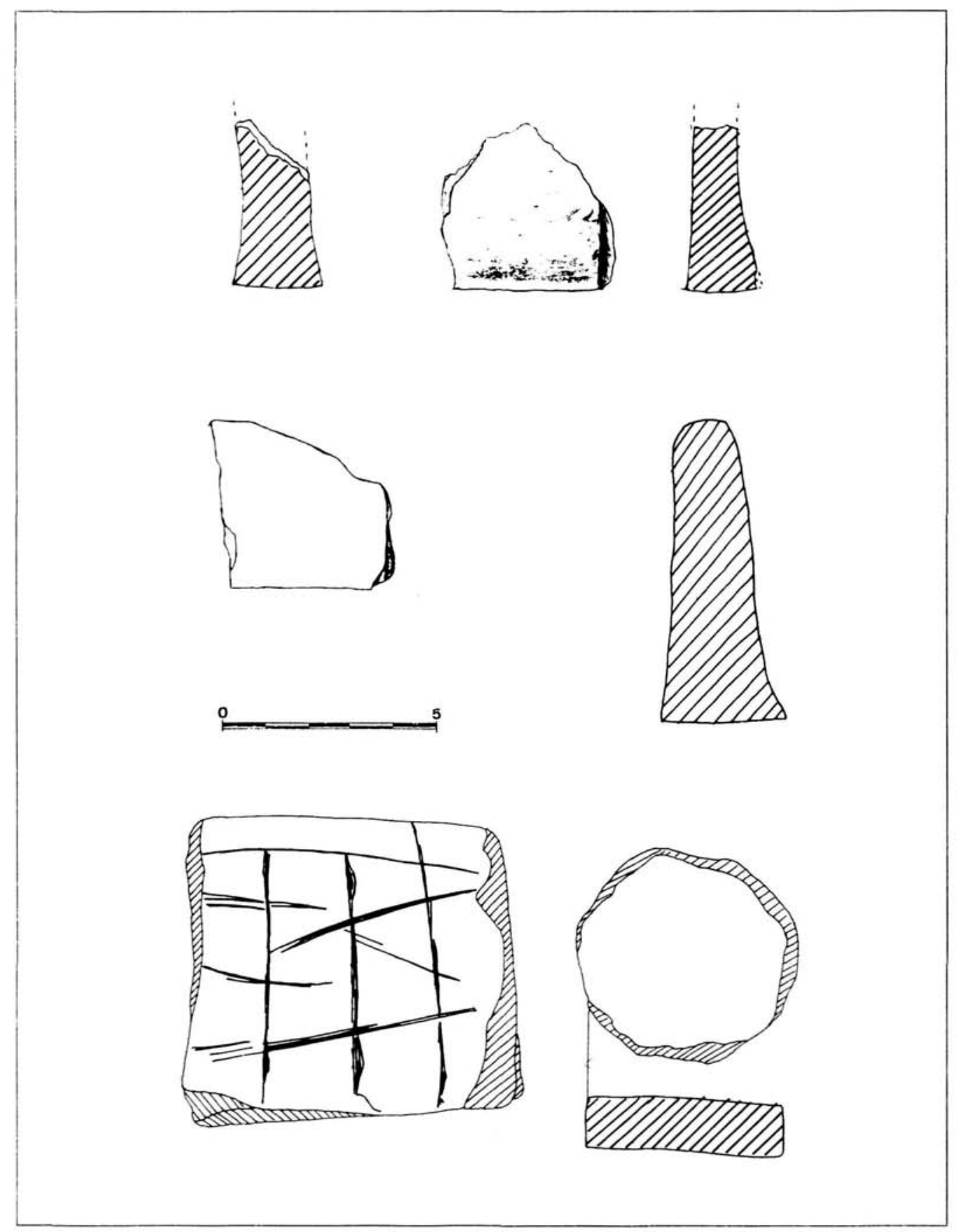

Figura 10. Fragmentos de morillos cerámicos y recorte discoidal. 


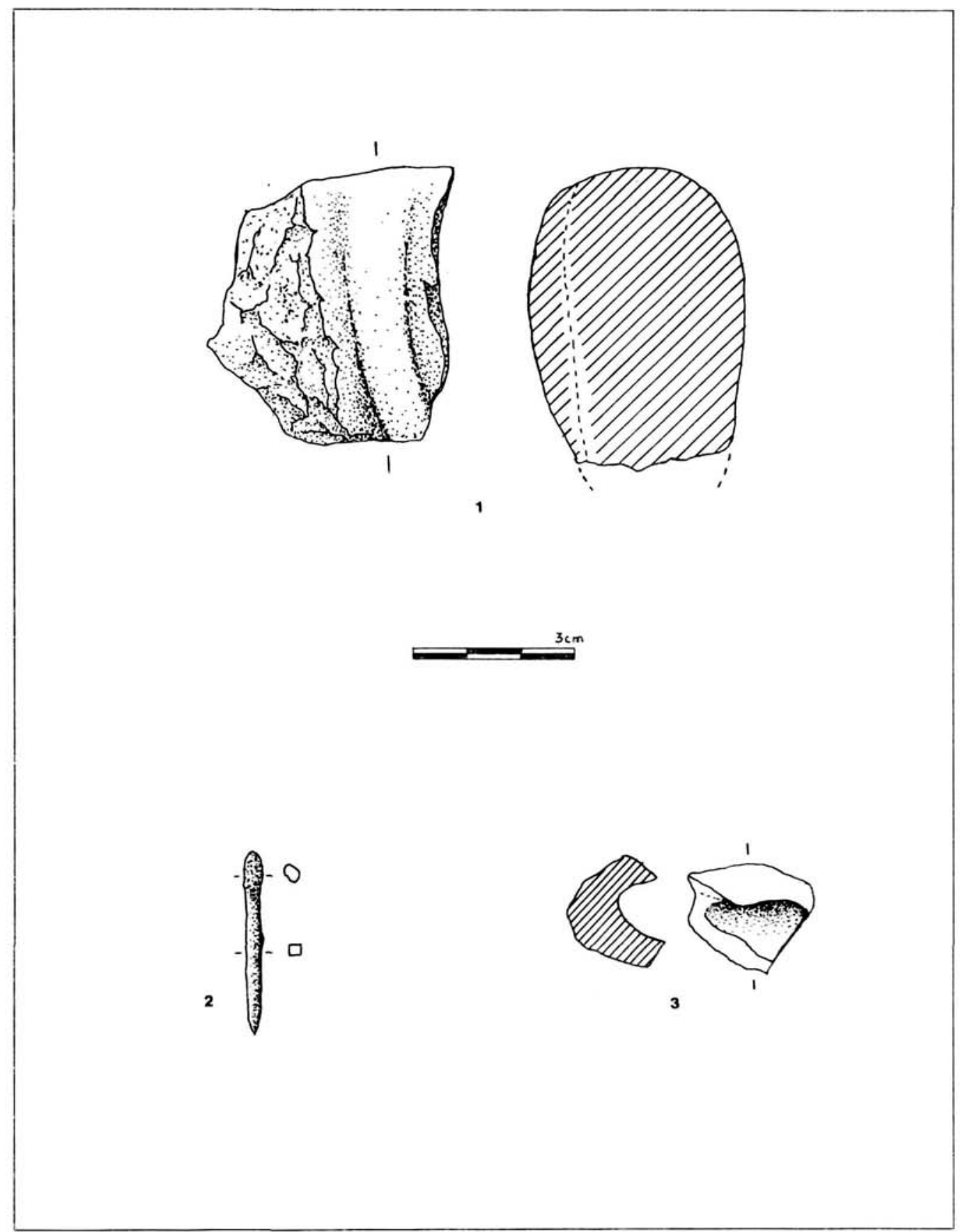

Figura 11. Materiales no cerámicos 1. Fragmento de hacha pulimentada.- 2. punzón de bronce.- 3 . hueso recortado y pulimentado. 
como el Sector III de Getafe (Blasco y Barrio, 1987) y San Antonio (Blasco, Lucas y Alonso, 1991) no alcanzaban proporciones tan altas como en este caso ni todos los fragmentos tienen un barniz de la calidad que encontramos en la Capellana, por ello, y por estar asociados a ejemplares realizados a mano, es por lo que los habíamos considerado como almagras, similares a las que encontramos en conjuntos del sudeste de similar cronología (González Prats, A., 1983, p. 121), las cuales habrían de ser revisadas por si en algún caso deben ser consideradas también barnices rojos aplicados sobre producciones indígenas realizadas todavía a mano, si ello es así, hay que plantearse la existencia de un primer momento de presencia fenicia en la Península, en el que las producciones de importación o realizadas por los propios fenicios de la Península, son rápidamente imitadas por alfareros locales que todavía no han incorporado el torno a sus producciones.

Este hecho parece comprensible entre los grupos indígenas más próximos a las colonias, como pueden ser algunos yacimientos granadinos del interior, o incluso no parece extraño que lo encontramos en puntos algo más distantes, pero con intensas relaciones como es el caso de Cástulo, donde estas almagras o barnices rojos sobre recipientes a mano son también abundantes, pero ya no resulta tan lógico entre gentes establecidas a unos centenares de kilómetros y, teóricamente lejos de los intereses comerciales prioritarios de los colonos, como es esta región norte de la submeseta sur, a no ser que las relaciones entre ambas áreas culturas sean más intensas y fluídas de lo que se ha venido pensando. una circuntancia que parece haberse producido, posiblemente, en parte, como consecuencia de una dilatada tradición de relaciones y, en parte también, por la existencia de nuevas necesidades comerciales o por otros intereses.

Al parecer, se dieron alguna o varias de estas circunstancias ya que no sólo encontramos producciones de barniz rojo en esta área del alto Tajo, sino que existen otros muchos elementos de similitud entre las zonas costeras meridionales afectadas por las primeras colonias y la zona que nos ocupa. Entre los paralelismos, resultan especialmente significativos los acabados a cepillo de las cerámicas comunes combinados o no, con impresiones de uñas o dedos o con gruesas incisiones que son muy abundantes en el Bronce Final del suroeste desde Extremadura (Almagro Gorbea, M. 1977, pp. 134-136) hasta Córdoba (López Palomo, L.A., 1981, pp. 118-122), si bien no puede olvidarse que este tipo de tratamiento aparece también en los conjuntos vasculares de otras áreas culturales peninsulares del Bronce Final como el Valle del Ebro (Castiella, A., 1977). Mucho más significativos de estas relaciones o contactos con el suroeste son los acabados bruñidos y, muy especialmente la existencia de alguna retícula bruñida desarrollada sobre la cara interna de alguna pieza bastante abierta, un tratamiento decorativo muy característico del Bronce del suroeste.

Así mismo las pequeñas cazuelas carenadas o de galbo redondeado acusado con decoraciones incisas, pintura postcoccción o con ambas técnicas combinadas tienen paralelos muy próximos en yacimientos coétaneos del sureste, un paralelismo que resulta más acusado si se tienen en cuenta otros aspectos como son los tratamientos muy bruñidos de las superficies oscuras y la extrema delgadez de las paredes de algunos ejemplares, auténticas "cáscaras de huevo", así como la sintaxis compositiva de los diseños, distribuídos en metopas.

La suma de todos estos aspectos cerámicos de "ambiente meridional", a los que se podrían añadir otros paralelos como es el urbanismo o las características de las estructuras arquitectónicas, nos pueden llevar a pensar que las relaciones entre el litoral meridional peninsular y, en general, la región bética y la submeseta sur debieron ser en estos momentos de inicios del primer milenio bastante más intensas y generalizadas de lo que tradicionalmente se había creído, ya que no se trata de una situación excepcional para el área de Madrid, sino que, a la luz de los datos 


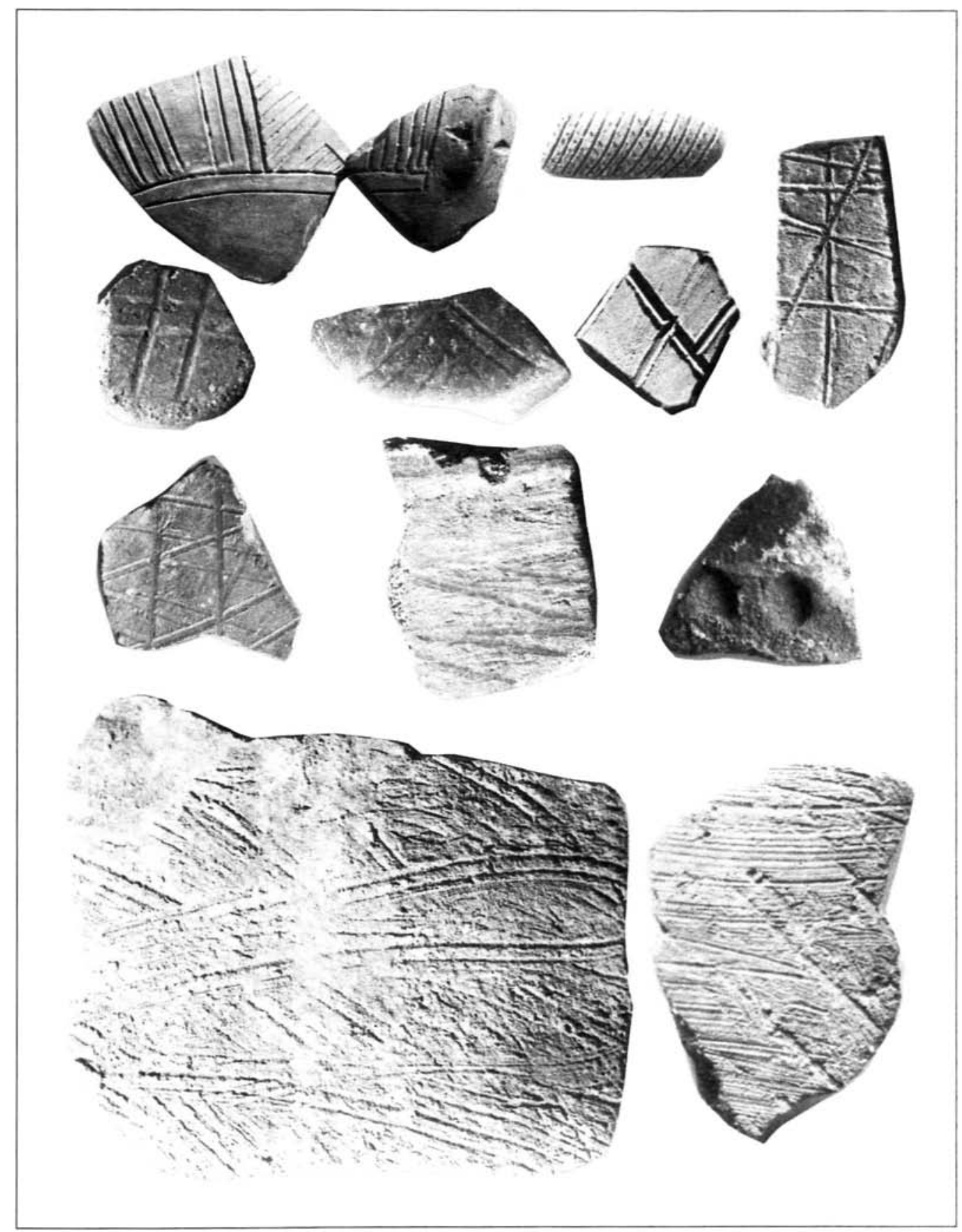

Lámina I. Detalle de diversas técnicas decorativas y de acabados "a cepillo". 


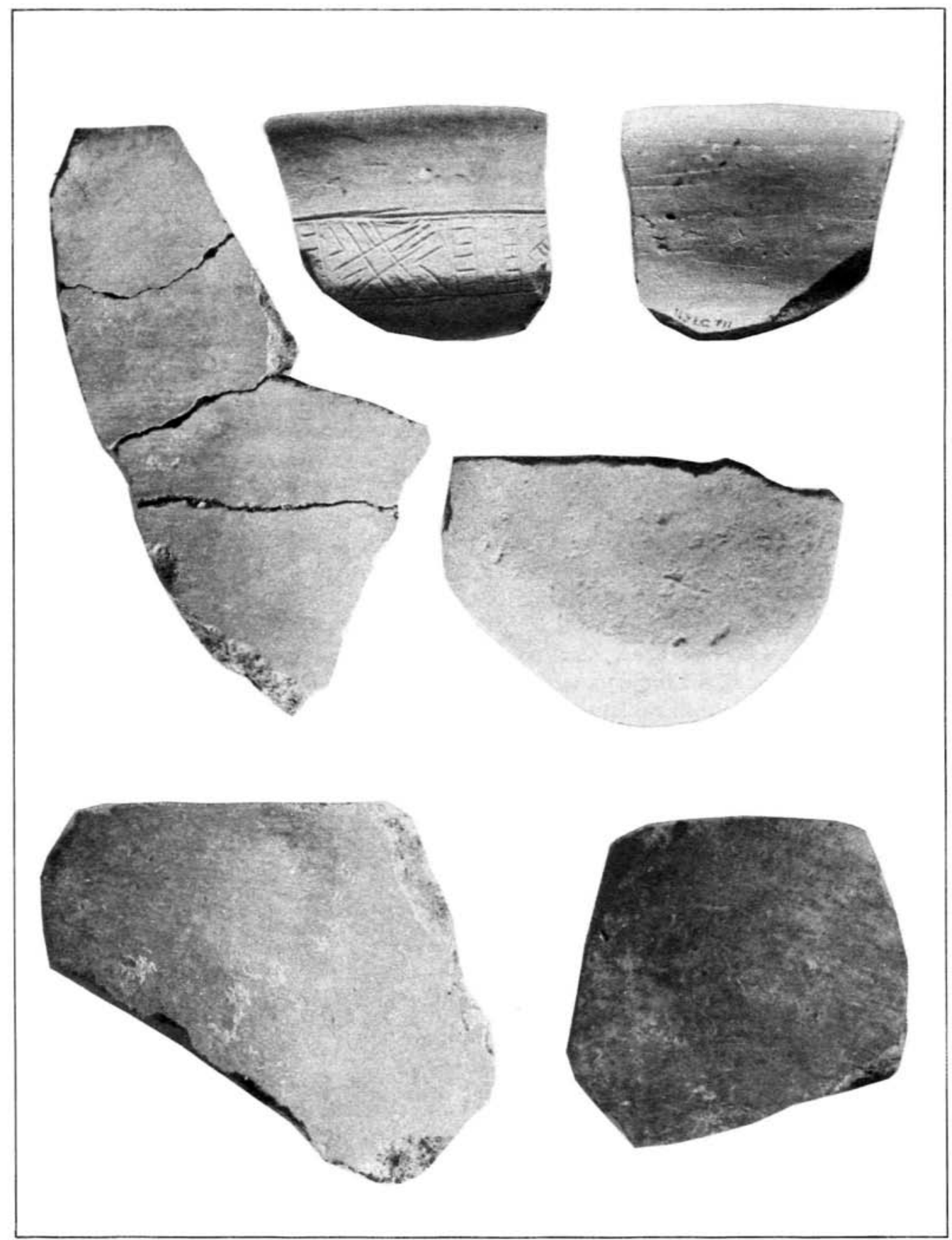

Lámina II. Aspecto de algunos de los engobes rojos. 
que la Arqueología está aportando en la última década, puede comprobarse que la presencia de elementos orientalizantes es bastante general, tanto en manifestaciones excepcionales como pueden ser las estelas del suroeste, localizadas en varios puntos de la propia de Ciudad Real, e incluso en tierras toledanas, o el importante hallazgo orientalizante de El Carpio identificado con una posible tumba (Pereira, J. y de Alvaro, E.,1988, pp. 279-289), como en producciones vasculares de utilización doméstica, como es el caso que nos ocupa.

Por otra parte, esta situación de relaciones con el sureste y sur penisnsular, explicaría bien la temprana iberización de buena parte de las tierras de la submeseta sur, proceso que se iniciaría en el siglo VI y creemos que estaría prácticamente consumado dentro del siglo V.

Aunque todavía resulta prematuro fijar la evolución de la I Edad del Hierro en estas tierras del interior peninsular. no nos parece arriesgado proponer que el yacimiento de La Capellana, con un volumen relativamente importante de acabados de engobe rojo que reproducen las calidades de los productos fenicios, y con una menor presencia de platos carenados que el Cerro de San Antonio, correspondería a un momento relativamente avanzado que habría que situar en pleno siglo VI sin que, por el momento, sea posible efectuar muchas más precisiones al no conocer este proceso en otras tierras de la submeseta sur que debieron de haber servido de enlace entre las regiones costeras y los grupos asentados en el Alto Tajo. 


\section{BIBLIOGRAFIA}

Almagro, M. 1977: El Bronce Final y el Período orientalizante en Extremadura. B. P. H. XIV. Madrid. ArteagA, O. y Serna, M. R. 1975: “Los Saladares-71". NA H Arqueologia, 3. Madrid, pp. 1-40.

BLASCO, C. y BaRRIO, J. 1986: "Excavaciones en dos nuevos asentamientos prehistóricos en Getafe (Madrid)". NAH 27. Madrid, pp. 75-142.

BlasCO, C, LuCAS, R. y Alonso, A. 1985: "Nuevo yacimiento prehistórico en la provincia de Madrid: El Cerro de San Antonio".Actas del XVII CAN. Zaragoza, pp. 267-276.

Blasco, C., Sanchez Capilla, L. y Calle J. 1990: "Madrid en el marco de la Primera Edad del Hierro de la Península Ibérica”. CuPAUAM, 15. Madrid, pp. 139-182.

CASTIELLA, A. 1977: La Edad del Hierro en Navarra y Rioja. Pamplona.

GarCia Gelabert, M.P. y Blazquez, J.M. 1988: Cástulo. I. Excavaciones en la necrópolis ibérica del Estacar de Robarinos (s. IV. antes de C.). BAR. Int. Series, 425. Oxford.

Gonzalez Prats, A. 1983: Estudio arqueológico del poblamiento antiguo de la Sierra de Crevillente (Alicante). Alicante.

...1985: "Los nuevos asentamientos del final de la Edad del Bronce. Problemática cultural y cronológica". Arqueologia del País valenciano: Panorama y perspectivas. Alicante, pp. 166 y ss.

Lopez Palomo, L. A. 1981: "Alhonoz: (Excavaciones de 1973 a 1978)". N.A.H.11. Madrid, pp. 33-187. PrIEGo, C. 1987: "Hierro I en la Meseta. El yacimiento de Puente I". Arqueologia no 16. Porto, pp. 96-108.

Rutz Mata D. y Fernandez Jurado, J. 1986: El yacimiento metalúrgico de época tártesica de San Bartolomé de Almonte (Huelva). Huelva Arqueológica, VIII, 1 y 2 